\title{
Can the presence of endoscopic high-risk stigmata be predicted before endoscopy? A multivariable analysis using the RUGBE database
}

\author{
Yen-I Chen $M D^{1}$, Jonathan Wyse $M D^{1}$, Alan Barkun MD MSc${ }^{1,2}$, Marc Bardou MD PhD ${ }^{3,4}$, \\ Ian M Gralnek MD MSHS ${ }^{5}$, Myriam Martel BSc${ }^{1}$
}

Y-I Chen, J Wyse, A Barkun, M Bardou, IM Gralnek, M Martel. Can the presence of endoscopic high-risk stigmata be predicted before endoscopy? A multivariable analysis using the RUGBE database. Can J Gastroenterol Hepatol 2014;28(6):301-304.

BACKGROUND: Many aspects in the management of acute upper gastrointestinal bleeding rely on pre-esophagogastroduodenoscopy (EGD) stratification of patients likely to exhibit high-risk stigmata (HRS); however, data predicting the presence of HRS are lacking.

OBJECTIVE: To determine clinical and laboratory predictors of HRS at the index EGD in patients presenting with acute upper gastrointestinal bleeding using retrospective data from a validated national database - the Canadian Registry in Upper Gastrointestinal Bleeding and Endoscopy registry.

METHODS: Relevant clinical and laboratory parameters were evaluated. HRS was defined as spurting, oozing, nonbleeding visible vessel or adherent clot after vigorous irrigation. Multivariable modelling was used to identify predictors of HRS including age, sex, hematemesis, use of antiplatelet agents, American Society of Anesthesiologists (ASA) classification, nasogastric tube aspirate, hemoglobin level and elapsed time from the onset of bleeding to EGD.

RESULTS: Of the 1677 patients (mean [ \pm SD] age $66.2 \pm 16.8$ years; $38.3 \%$ female), $28.7 \%$ had hematemesis, $57.8 \%$ had an ASA score of 3 to 5 , and the mean hemoglobin level was $96.8 \pm 27.3 \mathrm{~g} / \mathrm{L}$. The mean time from presentation to endoscopy was $22.2 \pm 37.5 \mathrm{~h}$. The best fitting multivariable model included the following significant predictors: ASA score 3 to 5 (OR 2.16 [95\% CI 1.71 to 2.74]), a shorter time to endoscopy (OR 0.99 [95\% CI 0.98 to 0.99]) and a lower initial hemoglobin level (OR 0.99 [95\% CI 0.99 to 0.99]).

CONCLUSION: A higher ASA score, a shorter time to endoscopy and lower initial hemoglobin level all significantly predicted the presence of endoscopic HRS. These criteria could be used to improve the optimal selection of patients requiring more urgent endoscopy.

Key Words: Bleeding; Endoscopy; High-risk; Stigmata; Stratification
Peut-on prédire la présence de stigmates endoscopiques à haut risque avant l'endoscopie? Une analyse multivariée au moyen de la base de données RUGBE

HISTORIQUE : De nombreux aspects de la prise en charge des saignements gastro-intestinaux supérieurs dépendent de la stratification, avant l'œsophagogastroduodénoscopie (OGD), des patients susceptibles de présenter des stigmates à haut risque (SHR). Cependant, on ne possède pas de données sur la présence des SHR.

OBJECTIF : Déterminer les prédicteurs cliniques et de laboratoire des SHR au moment de l'OGD de référence chez les patients présentant des saignements gastro-intestinaux supérieurs aigus au moyen de données rétrospectives tirées d'une base de données nationale validée, soit le Canadian Registry on Nonvariceal Upper Gastrointestinal Bleeding and Endoscopy.

MÉTHODOLOGIE : Les chercheurs ont évalué les paramètres cliniques et de laboratoire pertinents. Ils ont défini les SHR comme un vaisseau visible giclant, suintant et sans saignement ou un caillot adhérent après une irrigation vigoureuse. Ils ont utilisé un modèle multivarié pour déterminer les prédicteurs de SHR, y compris l'âge, le sexe, l'hématémèse, l'utilisation d'antiplaquettaires, la classification de l'American Society of Anesthesiologists (ASA), les aspirats de la sonde nasogastrique, le taux d'hémoglobine et le délai entre le début des saignements et l'OGD.

RÉSULTATS : Chez les 1677 patients (âge moyen [ \pm ÉT] 66,2 $\pm 16,8$ ans; $38,3 \%$ de femmes), 28, $7 \%$ avaient une hématémèse, $57,8 \%$ avaient une classification de l'ASA de 3 à 5 , et leur taux d'hémoglobine moyen était de $96,8 \pm 27,3 \mathrm{~g} / \mathrm{L}$. Le délai moyen entre la présentation et l'endoscopie était de $22,2 \pm 37,5$ heures. Le modèle multivarié le mieux adapté incluait les prédicteurs importants suivants : la classification de l'ASA de 3 à 5 (RC 2,16 [95 \% IC 1,71 à 2,74]), un délai plus court avant l'endoscopie (RC $0,99$ [95\% IC 0,98 à 0,99$]$ ) et un taux d'hémoglobine initial plus faible (RC 0,99 [95 \% IC 0,99 à 0,99]).

CONCLUSION : Une classification de l'ASA plus élevée, un délai plus court jusqu'à l'endoscopie et un taux d'hémoglobine initial plus court sont tous des prédicteurs importants de SHR endoscopiques. Ces critères pourraient être utilisés pour améliorer la sélection optimale des patients qui ont besoin d'une endoscopie plus urgente.
$A$ cute, nonvariceal upper gastrointestinal bleeding (NVUGIB) is a $A$ life-threatening condition that affects one per 1000 population per year, resulting in 250,000 to 300,000 hospitalizations and 15,000 to 30,000 deaths per year in the United States $(1,2)$. More than $\$ 2.5$ billion are spent on the care of these patients each year (2). Medical management begins with appropriate resuscitation and risk stratification (3). Identification of high-risk patients enables appropriate intervention to reduce mortality and morbidity while maximizing cost effectiveness. Risk stratification scoring tools, such as the Rockall and Glasgow-Blatchford scores (GBS), have been investigated in predicting high-risk patients (4-6). The GBS classification is a pre-endoscopic scale that uses hemoglobin, blood urea, heart rate, systolic blood pressure, the presence of syncope or melena, and evidence of hepatic or cardiac failure to identify low-risk patients who do not require clinical intervention. The full Rockall score, which has been validated in multiple countries (7-9), takes into account clinical parameters such as age, hemodynamics and comorbidities (which in their own right form the clinical Rockall score that bears prognostic information), as well as endoscopic findings and presence of endoscopic stigmata in assessing risk for rebleeding and mortality.

These scores are not routinely used; some are not easy to calculate, while others include subjective variables. Although these scoring tools

${ }^{1}$ Division of Gastroenterology; ${ }^{2}$ Departments of Epidemiology and Biostatistics, and Occupational Health, McGill University Health Centre, McGill University, Montréal, Québec; ${ }^{3}$ INSERM-Centre d'Investigations Cliniques Plurithématique 803 (CIC-P 803), CHU du Bocage; Dijon; ${ }^{4}$ Service d'hépato-gastroentérologie, CHU du Bocage; Dijon, France; 5 Department of Gastroenterology, Rambam Health Care Campus, Rappaport Faculty of

Medicine, Technion-Israel Institute of Technology, Haifa, Israel

Correspondence: Dr Alan Barkun, Division of Gastroenterology, The McGill University Health Centre, Montreal General Hospital site, 1650 Cedar Avenue, Room D7-346, Montreal, Quebec H3G 1A4. Telephone 514-934-8309, fax 514-834-8531, e-mail alan.barkun@muhc.mcgill.ca

Received for publication January 27, 2014. Accepted February 17, 2014 
have been validated in recognizing high-risk patients, models that more specifically predict the presence of high-risk stigmata (HRS), which has a significant impact on prognosis and management, are lacking (3). HRS is characterized by esophagogastroduodenoscopy (EGD) findings of active bleeding (both spurting and oozing, Forrest Ia and Ib), a nonbleeding visible vessel (IIa) or an adherent clot (IIb). Early endoscopy may be most beneficial in this subgroup of patients $(3,10)$. The goal of the present study was, thus, to identify clinical and laboratory predictors of HRS in patients with NVUGIB using the Registry in Upper Gastrointestinal Bleeding and Endoscopy (RUGBE) national registry. These identified predictors could then be used to improve the optimal selection of individuals requiring more urgent endoscopy.

\section{METHODS}

\section{Patient population}

The Canadian RUGBE registry is a multicentre retrospective database that collected descriptive data on 1869 patients with NVUGIB managed in 18 university and community centres across Canada between 1999 and 2002. The RUGBE initiative, methods of data collection and validation of the data have been previously described $(11,12)$. The study population consisted of all patients presenting for medical attention because of overt upper gastrointestinal (GI) bleeding or a history of hematemesis/coffee-ground vomiting, melena, hematochezia or a combination thereof within the $24 \mathrm{~h}$ preceding admission. Furthermore, upper GI bleeding was confirmed only if a member of the medical or nursing staff documented and witnessed hematemesis, melena or the recovery of bloody nasal gastric aspirate, or if they noted black tarry material on rectal examination $(11,12)$. Patients were entered in the registry only if an upper GI endoscopy was performed. Patients in whom esophageal, gastric or duodenal varices were noted to be the source of bleeding were excluded from the registry.

Only a sampling of eligible patients during the period of registry data collection was purposefully included. This sampling was performed at regular intervals using randomly varying sequential time series to avoid any systematic bias in patient selection. An audit of all patients presenting over a fixed time period at each participating institution was performed to confirm the absence of selection bias using a $10 \%$ audit of source data verification by an independent study nurse.

For the purposes of this secondary analysis, all patients transferred from another institution not part of RUGBE were excluded because the authors have done this in other published post hoc analyses, yielding a total of 1677 patients for the current analysis $(11,12)$.

\section{RUGBE database variables}

The full RUGBE database is comprised of 217 variables, including demographic (age, sex, site, date of endoscopy) and historical data (presenting symptoms, comorbid conditions, health status on presentation using the American Society of Anesthesiologists [ASA] classification, medical history, medication intake, thorough documentation of the time of onset of bleeding and the time of first presentation to a medical facility). Furthermore, the physical examination findings (hemodynamic data, rectal and nasogastric [NG] tube findings), initial laboratory data (complete blood count, prothrombin time, platelets), and resuscitative efforts (type and quantity of fluids, time of administration) were recorded. The endoscopic-related variables of the database followed the Minimal Standard Terminology (13), including the description of the bleeding lesion and stigmata of bleeding, and the timing, nature and number of hemostatic procedures, when performed. HRS were defined as an adherent clot (after vigorous irrigation) or a bleeding (oozing or spurting) or nonbleeding visible vessel (ie, pigmented protuberance). Other diagnostic or therapeutic intervention, such as pharmacological therapies, surgery or angiography, and important information related to Helicobacter pylori infection during the initial bleeding episode, were also recorded.

A total of 12 independent variables considered to be clinically relevant by investigators and based on evidence in the literature in predicting HRS were identified (11). These included age, sex, hematemesis, ASA classification, hemodynamic instability, NG tube aspirate, hemoglobin level, elapsed time from onset of bleeding to EGD, use of antiplatelet agents, nonsteroidal anti-inflammatry drugs (NSAIDs) and proton pump inhibitors (PPIs). The data collection did not enable determination of whether the administration of PPIs occurred before or after endoscopy.

\section{Statistical analysis}

Continuous variables were reported as SDs (or median and ranges, where appropriate), with a Wilcoxon nonparametric test to explore possible associations between high- and low-risk stigmata. Categorical variables were reported as proportions and $95 \%$ CIs, with inferential analysis performed using $\chi^{2}$ testing. A level of significance of $\mathrm{P} \leq 0.05$ was adopted for all inferential testing. Standard stepwise logistic regression analysis techniques were used to identify predictors of HRS from the aforementioned clinically relevant variables that were found to be of interest based on univariable analysis. All analyses were performed using SAS version 9.2 (SAS Institute, USA).

\section{Ethics}

Institutional ethics review boards from all participating centres approved this registry. The approval from the director of professional services was also obtained at all sites. In addition, patient consent was obtained where required by local regulations.

\section{RESULTS}

\section{Patient population}

The RUGBE data set has been described previously in detail $(11,12)$. The mean $( \pm$ SD) age of the cohort was $66.2 \pm 16.8$ years, with $38.3 \%$ female and a mean of $2.5 \pm 1.7$ comorbidities. Hematemesis was noted in $28.7 \%$ of the subjects while $40.6 \%$ took acetylsalicylic acid, $22.5 \%$ a traditional NSAID, 3.3\% a cyclooxyegenase-2 inhibitor and $84.4 \%$ a PPI. An ASA score of 3 to 5 was observed in $57.8 \%$ of the patients. NG tube aspirate exhibited coffee-ground material or bright red blood in $11.8 \%$ and $8.6 \%$ of cases, respectively. The mean hemoglobin level was $96.8 \pm 27.3 \mathrm{~g} / \mathrm{dL}$. Finally, the mean time from onset of bleed to endoscopy was $22.2 \pm 37.5 \mathrm{~h}$. HRS were noted in 601 (35.8\%) of the 1677 patients. Length of hospitalization was $5.3 \pm 5.6$ days in patients without HRS and $6.3 \pm 6.7$ days in patients with HRS $(\mathrm{P}<0.0001)$. Overall mortality in patients with or without HRS was $4.2 \%(95 \% \mathrm{CI}$ $3.0 \%$ to $5.5 \%$ ) and $7.4 \%$ (95\% CI $5.3 \%$ to $9.5 \%$ ), respectively.

\section{Univariable analysis}

The clinically relevant patient demographics, laboratory variables, clinical data and procedural characteristics stratified according to the presence of HRS at EGD are shown in Table 1. Shorter time to endoscopy best predicted the presence of HRS in univariate analysis; although a significant majority of patients received a PPI, no inferential analysis could be performed on PPI use due to lack of information regarding the chronology vis-à-vis EGD; however, it is included in Table 1 as descriptive information. Clinical variables, such as bright red blood per NG tube, postural blood pressure changes, higher ASA scores ( 3 to 5 ) and lower hemoglobin levels, were also significantly associated with HRS on endoscopy. Other factors including age, female sex, hematemesis and acetylsalicylic acid/NSAID/ticlopidine use on presentation did not contribute significantly to the prediction of HRS. ROC curve analysis suggested respective optimal cut-offs of $69 \mathrm{~g} / \mathrm{L}$ for hemoglobin, and of $21.5 \mathrm{~h}$ for time to endoscopy.

\section{Multivariable analysis}

The results of multivariate analysis on the parameters selected for the final model, including their OR and 95\% CI, are shown in Table 2. Significant predictors of HRS at EGD included ASA score, time to endoscopy and hemoglobin level. Both the presence of postural blood pressure changes and bright red blood per NG tube did not maintain their significance in the multivariable analysis. The 
TABLE 1

Univariate analysis of clinical and laboratory predictors of high-risk stigmata

\begin{tabular}{|c|c|c|c|}
\hline \multirow[b]{2}{*}{$\begin{array}{l}\text { Characteristic at } \\
\text { presentation }\end{array}$} & \multicolumn{2}{|c|}{ Stigmata } & \multirow[b]{2}{*}{$\mathbf{P}$} \\
\hline & $\begin{array}{l}\text { Low risk } \\
(n=1076)\end{array}$ & $\begin{array}{l}\text { High risk } \\
(\mathrm{n}=601)\end{array}$ & \\
\hline Age, years, mean $\pm S D$ & $66.4 \pm 17.2$ & $65.8 \pm 16.0$ & 0.2581 \\
\hline Male sex & $61.0(57.7-63.5)$ & $63.7(59.9-67.6)$ & 0.2057 \\
\hline ASA score 3,4 or 5 & $50.5(47.5-53.5)$ & $71.1(67.4-74.7)$ & $<0.0001$ \\
\hline Hematemesis & $27.8(25.1-30.5)$ & $30.3(26.6-34.0)$ & 0.2745 \\
\hline PPI use* & $79.7(77.3-82.1)$ & $92.7(90.6-94.8)$ & \\
\hline $\begin{array}{l}\text { Acetylsalicylic acid use } \\
\text { on presentation }\end{array}$ & $41.0(38.1-44.0)$ & $39.8(35.8-43.7)$ & 0.6096 \\
\hline $\begin{array}{l}\text { NSAID(s) use on } \\
\text { presentation }\end{array}$ & $22.5(20.0-25.1)$ & $22.4(19.1-25.8)$ & 0.9490 \\
\hline $\begin{array}{l}\text { Ticlopidine use on } \\
\text { presentation }\end{array}$ & $1.0(0.4-1.6)$ & $1.7(0.6-2.7)$ & 0.2574 \\
\hline $\begin{array}{l}\text { Postural changes } \\
\text { present }\end{array}$ & $28.2(25.3-31.0)$ & $37.8(33.7-41.9)$ & $<0.0001$ \\
\hline $\begin{array}{l}\text { Bright red blood on } \\
\text { nasogastric tube } \\
\text { aspirate }\end{array}$ & $6.4(5.0-7.9)$ & $12.3(9.7-15.0)$ & $<0.0001$ \\
\hline \multicolumn{4}{|l|}{ Hemoglobin level, g/L } \\
\hline $\begin{array}{l}\text { At presentation, } \\
\text { mean } \pm \text { SD }\end{array}$ & $99.7 \pm 27.7$ & $91.8 \pm 25.6$ & $<0.0001$ \\
\hline $100-120$ & $22.0(19.4-24.5)$ & $17.0(14.4-20.5)$ & 0.0288 \\
\hline $70-120$ & $62.5(59.6-65.5)$ & $65.7(61.8-69.5)$ & 0.2049 \\
\hline$\leq 70$ & $13.1(11.1-15.2)$ & $18.6(15.5-21.8)$ & 0.0030 \\
\hline Blood transfusion & $45.5(42.6-48.5)$ & $68.2(64.5-72.0)$ & $<0.0001$ \\
\hline $\begin{array}{l}\text { Time to endoscopy, } \mathrm{h} \text {, } \\
\text { mean } \pm \text { SD }\end{array}$ & $26.4 \pm 38.8$ & $17.6 \pm 34.2$ & $<0.0001$ \\
\hline
\end{tabular}

Data presented as \% $(95 \% \mathrm{Cl})$ unless otherwise indicated. ${ }^{*}$ Proton pump inhibitor (PPI) use included exposure both pre- and postendoscopy and, thus, was not used for inferential analysis. ASA American Society of Anesthesiologists; NSAIDs Nonsteroidal anti-inflammatory drugs

best-fitting multivariable model included a high ASA score (3 to 5) (OR 2.160 [95\% CI 1.705 to 2.737]), time to endoscopy (per hour) (OR 0.998 [95\% CI 0.983 to 0.993]) and hemoglobin level (per $10 \mathrm{~g} / \mathrm{L})(\mathrm{OR}$ 0.992 [95\% CI 0.988 to 0.997$])$.

\section{DISCUSSION}

Although risk-stratification scoring tools, such as the Rockall and GBS, have made strides in improving diagnostic accuracy and shorter duration of hospitalization in NVUGIB, data regarding predictors of HRS are lacking. Individuals with HRS are those who benefit most from endoscopy because endoscopic hemostasis can be achieved and this has been shown to significantly reduce rebleeding $(14,15)$; therefore, a better understanding of which variables may be likely to predict HRS could optimize patient selection for more urgent endoscopy.

According to our data, patients with an ASA score $\geq 3$, a lower initial hemoglobin level at the time of patient presentation and a shorter elapsed time to endoscopy predicted an increased risk of finding HRS on endoscopy. The hemoglobin variable can be interpreted as an increased risk of HRS with every incremental drop of $10 \mathrm{~g} / \mathrm{L}$ in hemoglobin level. Time to endoscopy, on the other hand, is on a per hour basis, meaning that each hour in delay of endoscopy reduces the likelihood of finding HRS. This may be explained by the fact that early endoscopy is usually performed on the sickest patients who have the highest probability of having HRS, while patients who receive delayed endoscopy are usually stable and, hence, have a lower likelihood of having lesions with high-risk features in addition to having a longer healing time. The clinical usefulness of these predictors is highlighted in Figure 1. For a patient with ASA score 3 to 5, hemoglobin level $<70 \mathrm{~g} / \mathrm{L}$ and endoscopy within $12 \mathrm{~h}$, the probability of finding HRS would be $58 \%$, which is in contrast to a patient with ASA score
TABLE 2

Multivariable analysis of clinical and laboratory predictors of high-risk stigmata

\begin{tabular}{lcr}
\hline Variable & OR $(95 \%$ CI) & P \\
\hline ASA score 3 to 5 & $2.160(1.705-2.737)$ & $<0.0001$ \\
Postural BP changes present & $1.203(0.948-1.525)$ & 0.1283 \\
Time to endoscopy per hour & $0.988(0.983-0.993)$ & $<0.0001$ \\
Bright red blood per NG tube aspirate & $1.464(0.985-2.175)$ & 0.0591 \\
Hemoglobin level at presentation & $0.992(0.988-0.997)$ & 0.0004
\end{tabular}

per $\mathrm{g} / \mathrm{L}$

ASA American Society of Anesthesiologists; BP Blood pressure; NG Nasogastric

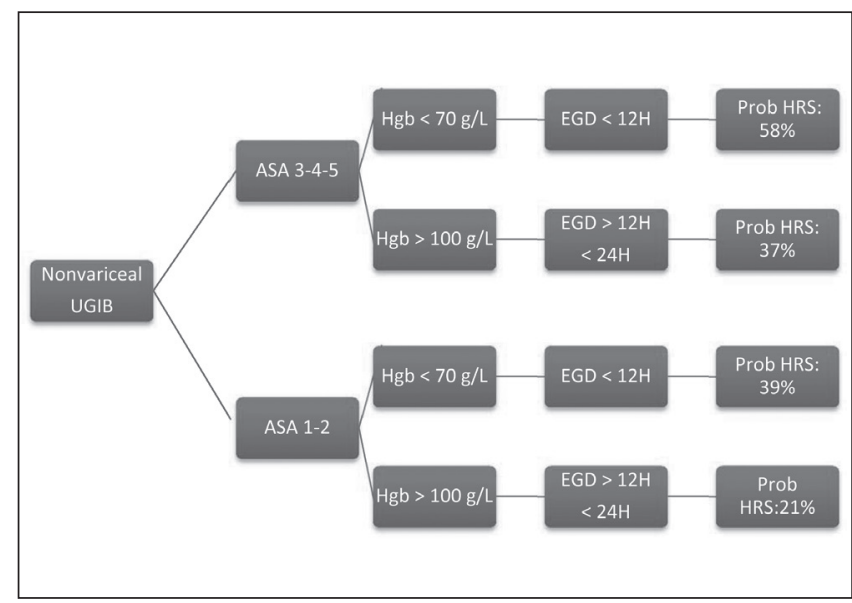

Figure 1) Clinical scenarios predicting high-risk stigmata (HRS). ASA American Society of Anesthesiologists; EGD Esophagogastroduodenoscopy; Hgb Hemoglobin; Prob Probability; UGIB Upper gastrointestinal bleeding

1 to 2 , hemoglobin level $>100 \mathrm{~g} / \mathrm{L}$, and time to endoscopy within $24 \mathrm{~h}$ but more than $12 \mathrm{~h}$, resulting in a 21\% likelihood of finding HRS. Figure 1 also displays the probabilities of finding HRS for clinical scenarios between these two extremes.

PPI use was not included in the final model because the RUGBE database does not specify whether medication was initiated pre- or postendoscopy (the RUGBE study was designed before the publication of most of the pre-endoscopy PPI information). Removal of PPI exposure from the multivariable model de facto assumes that all patients had the same PPI exposure, which is congruent with contemporary practice in which almost every patient receives a PPI before endoscopy because of its reported down-staging of high-risk lesions (16). If anything, assuming varying PPI exposure would not invalidate the value of the identified HRS predictors (only the respective OR estimates); it would only mask additional predictors whose value is obscured by the PPI HRS down-staging effect.

Our analysis was limited by the fact that it was a retrospective observational study, which is subject to selection bias. Despite major efforts in ensuring random sampling of the selected patients and validation of data, selection bias could have occurred at the level of enrollment into the registry.

Current recommendations in the management of UGIB suggest early endoscopy (defined as within $24 \mathrm{~h}$ of presentation) in most patients with NVUGIB $(3,17)$. In addition, very early endoscopy $(<12 \mathrm{~h})$ compared with early endoscopy ( $>12 \mathrm{~h},<24 \mathrm{~h}$ ) does not appear to confer any additional benefit in terms of rebleeding, need for surgery or mortality in unselected patients with NVUGIB (18-20). However, Lim et al (14) recently showed that in selected high-risk patients, defined as GBS $>12$, endoscopy within $13 \mathrm{~h}$ of presentation was associated with lower mortality. HRS was present in $70 \%$ of the high-risk subjects and only $25 \%$ of the low-risk group compared with similar risk predictions of $58 \%$ and $21 \%$ using the current proposed model that is based on fewer parameters and solely objective ones. Use of the GBS is, in 
contrast, tedious, with multiple variables required including inclusion of subjective assessments. Consistent with previous studies, these lowrisk subjects with minimal presence of HRS did not have a mortality benefit with endoscopy within $13 \mathrm{~h}$. Although possibly affected by confounders, these data highlight the importance of predicting HRS and its potential impact on the selection of individuals for very early endoscopy. Moreover, a recent study by Jairath et al (21) demonstrated that earlier endoscopy (within $12 \mathrm{~h}$ ) may be associated with increased efficiency of care and improved control of hemorrhage in high-risk patients, supporting a recent United Kingdom guideline that recommends endoscopy immediately following resuscitation in patients at increased risk of negative outcomes (22).

Our suggested risk stratification model uses fewer variables than either the GBS or Rockall, and includes only pre-endoscopy variables. The use of GBS or Rockall can be tedious, which may discourage its use by clinicians. In fact, a randomized controlled trial involving 42 Canadian centres investigating the adherence to guidelines in the management of NVUGIB following an educational intervention (23) demonstrated very low to nonexisting use of the Rockall or GBS score. The proposed model significantly simplifies risk stratification, which may encourage the clinician to use it in clinical practice, enabling better and, possibly, more cost-effective patient care. At the very least, it should remind clinicians of the need for appropriate and timely risk stratification to optimize care using objective, evidence-based evaluative tools.

The utility of our model with regard to PPI use is limited by the removal of this variable from the multivariable analysis as discussed

\section{REFERENCES}

1. Gilbert DA. Epidemiology of upper gastrointestinal bleeding. Gastrointest Endosc 1990;36:S8-13.

2. Johanson JF. Curbing the costs of GI bleeding. Am J Gastroenterol 1998;93:1384-5.

3. Barkun AN, Bardou M, Kuipers EJ, et al. International consensus recommendations on the management of patients with nonvariceal upper gastrointestinal bleeding. Ann Intern Med 2010;152:101-13.

4. Masaoka T, Suzuki H, Hori S, Aikawa N, Hibi T. Blatchford scoring system is a useful scoring system for detecting patients with upper gastrointestinal bleeding who do not need endoscopic intervention. J Gastroenterology Hepatol 2007;22:1404-8.

5. Rockall TA, Logan RF, Devlin HB, Northfield TC. Risk assessment after acute upper gastrointestinal haemorrhage. Gut 1996;38:316-21.

6. Romagnuolo J, Barkun AN, Enns R, Armstrong D, Gregor J. Simple clinical predictors may obviate urgent endoscopy in selected patients with nonvariceal upper gastrointestinal tract bleeding. Arch Intern Med 2007;167:265-70.

7. Camellini L, Merighi A, Pagnini C, et al. Comparison of three different risk scoring systems in non-variceal upper gastrointestinal bleeding. Dig Liver Dis 2004;36:271-7.

8. Enns RA, Gagnon YM, Barkun AN, Armstrong D, Gregor JC, Fedorak RN. Validation of the Rockall scoring system for outcomes from non-variceal upper gastrointestinal bleeding in a Canadian setting. World J Gastroenterol 2006;12:7779-85.

9. Vreeburg EM, Terwee CB, Snel P, et al. Validation of the Rockall risk scoring system in upper gastrointestinal bleeding. Gut 1999;44:331-5.

10. Cook DJ, Guyatt GH, Salena BJ, Laine LA. Endoscopic therapy for acute nonvariceal upper gastrointestinal hemorrhage: A meta-analysis. Gastroenterology 1992;102:139-48.

11. Aljebreen AM, Fallone CA, Barkun AN. Nasogastric aspirate predicts high-risk endoscopic lesions in patients with acute upperGI bleeding. Gastrointest Endosc 2004;59:172-8.

12. Barkun A, Sabbah S, Enns R, et al. The Canadian Registry on Nonvariceal Upper Gastrointestinal Bleeding and Endoscopy (RUGBE): Endoscopic hemostasis and proton pump inhibition are associated with improved outcomes in a real-life setting. Am J Gastroenterol 2004;99:1238-46.

13. Minimal standard terminology in digestive endoscopy. Endoscopy 2000;32:162-88.

14. Lim LG, Ho KY, Chan YH, et al. Urgent endoscopy is associated with lower mortality in high-risk but not low-risk nonvariceal upper gastrointestinal bleeding. Endoscopy 2011;43:300-6. above. However, once again, current practice is to administer a PPI before endoscopy in most patients with suspected upper GI bleeding based on randomized trial data that suggest downstaging of HRS, even though patient outcomes are not improved $(16,24)$. A subsequent determination of predictors of HRS in the context of varying exposure to PPI pre-endoscopy may help guide such optimal pharmacological use.

Finally, predictors of HRS may help decide on early intervention in the very ill or actively bleeding patients, especially in a setting where subsequent transfer to a more specialized centre may be contemplated, in which case identification of the likelihood of a HRS lesion becomes significantly more critical to immediate management. Such predictions may, for example, help to identify patients who could most benefit from novel therapies, such as Hemospray (Cook Medical, USA), that may be especially useful in achieving initial hemostasis $(25,26)$.

\section{CONCLUSION}

Using the RUGBE database and logistic regression analysis, three clinical predictors of HRS for NVUGIB were isolated in the present study: ASA score 3 to 5 , time to endoscopy and mean hemoglobin on presentation. The ability to predict HRS may aid in selecting patients who may benefit from very early endoscopy.

DISCLOSURES: The authors have no financial disclosures or conflicts of interest to declare.
15. Barkun AN. Should every patient with suspected upper GI bleeding receive a proton pump inhibitor while awaiting endoscopy? Gastrointest Endosc 2008;67:1064-6.

16. Lau JY, Leung WK, Wu JC, et al. Omeprazole before endoscopy in patients with gastrointestinal bleeding. $\mathrm{N}$ Engl J Med 2007;356:1631-40.

17. Gralnek IM, Barkun AN, Bardou M. Management of acute bleeding from a peptic ulcer. N Engl J Med 2008;359:928-37.

18. Bjorkman DJ, Zaman A, Fennerty MB, Lieberman D, Disario JA, Guest-Warnick G. Urgent vs. elective endoscopy for acute nonvariceal upper-GI bleeding: An effectiveness study. Gastrointest Endosc 2004;60:1-8.

19. Lee JG, Turnipseed S, Romano PS, et al. Endoscopy-based triage significantly reduces hospitalization rates and costs of treating upper GI bleeding: A randomized controlled trial. Gastrointest Endosc 1999;50:755-61.

20. Lin HJ, Wang K, Perng CL, et al. Early or delayed endoscopy for patients with peptic ulcer bleeding. A prospective randomized study. J Clin Gastroenterol 1996;22:267-71.

21. Jairath V, Kahan BC, Logan RF, et al. Outcomes following acute nonvariceal upper gastrointestinal bleeding in relation to time to endoscopy: Results from a nationwide study. Endoscopy 2012;44:723-30.

22. Dworzynski K, Pollit V, Kelsey A, Higgins B, Palmer K. Management of acute upper gastrointestinal bleeding: Summary of NICE guidance. BMJ 2012;344:e3412.

23. Barkun AN, Bhat M, Armstrong D, et al. Effectiveness of disseminating consensus management recommendations for ulcer bleeding: A cluster randomized trial. CMAJ 2013;185:E156-66.

24. Sreedharan A, Martin J, Leontiadis GI, et al. Proton pump inhibitor treatment initiated prior to endoscopic diagnosis in upper gastrointestinal bleeding. Cochrane Database Syst Rev 2010;(7):CD005415.

25. Sung JJY, Luo D, Wu JCY, et al. Early clinical experience of the safety and effectiveness of Hemospray in achieving hemostasis in patients with acute peptic ulcer bleeding. Endoscopy 2011;43:291-5.

26. Giday SA, Kim Y, Krishnamurty DM, et al. Long-term randomized controlled trial of a novel nanopowder hemostatic agent (TC-325) for control of severe arterial upper gastrointestinal bleeding in a porcine model. Endoscopy 2011;43:296-9. 


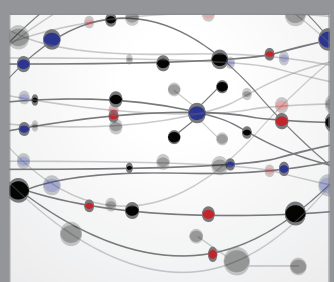

The Scientific World Journal
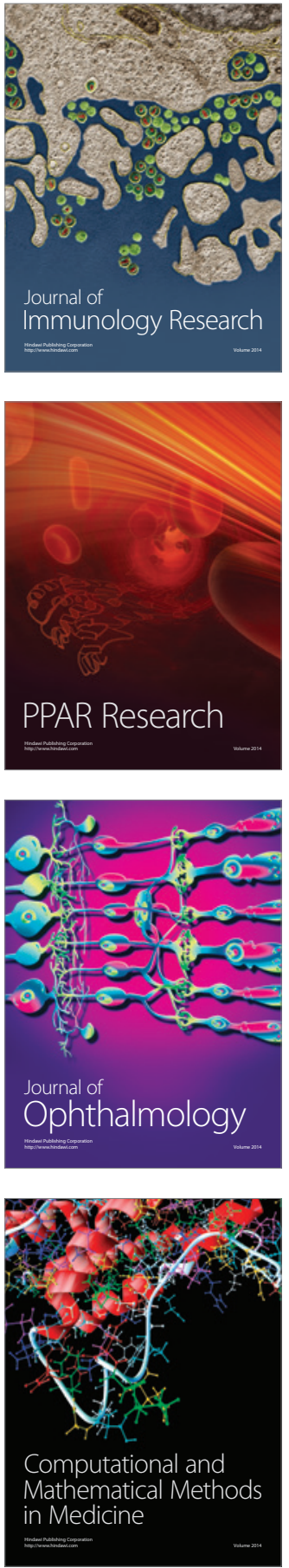

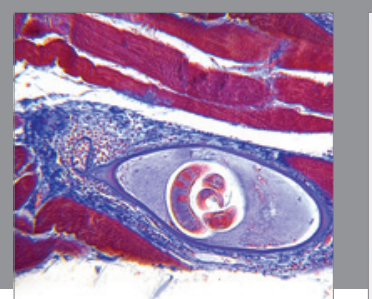

Gastroenterology Research and Practice

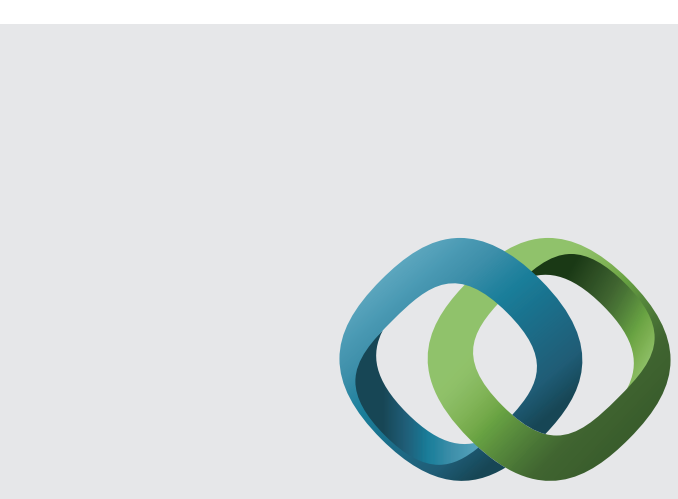

\section{Hindawi}

Submit your manuscripts at

http://www.hindawi.com
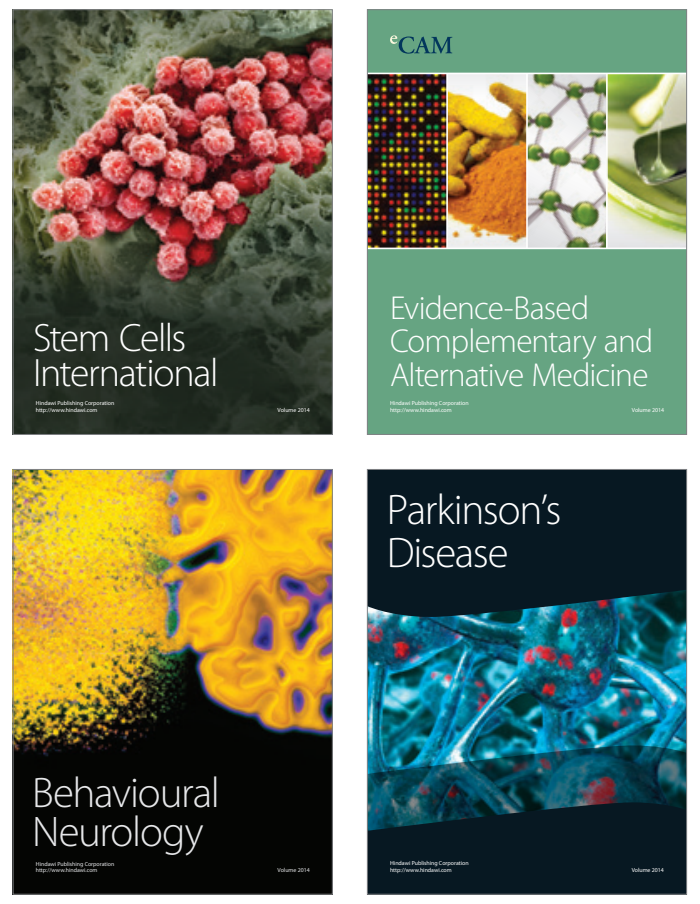
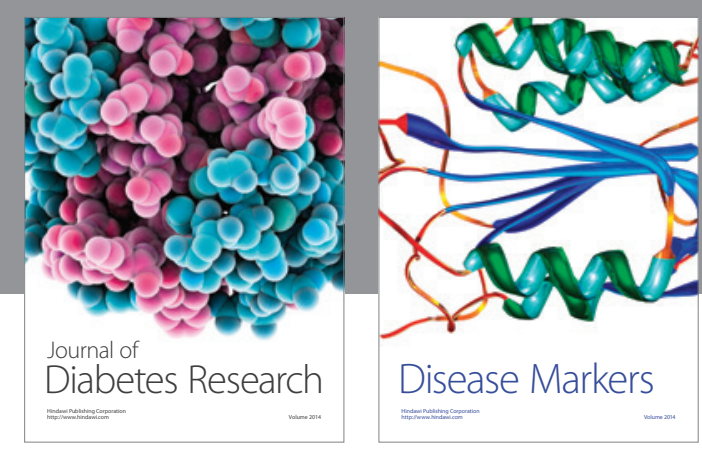

Disease Markers
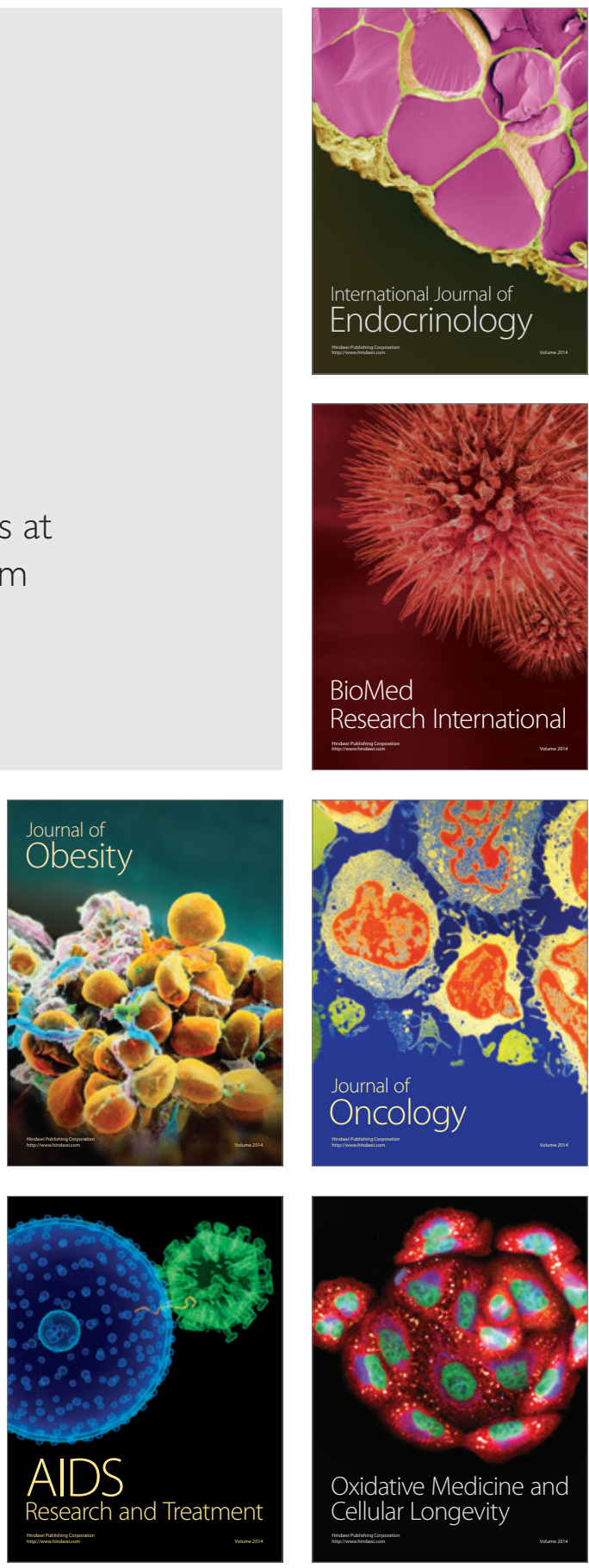